\title{
Towards Emotion Awareness Tools to Support Emotion and Appraisal Regulation in Academic Contexts
}

Elise Lavoué ${ }^{*}$, Maedeh Kazemitabar ${ }^{2}$, Tenzin Doleck ${ }^{2}$, Susanne P. Lajoie ${ }^{2}$, Rubiela Carrillo $^{3}$, Gaëlle Molinari ${ }^{4}$

${ }^{1}$ University of Lyon, University Jean Moulin Lyon 3, iaelyon school of Management, CNRS, LIRIS, France

${ }^{2}$ McGill University, Montreal, Canada

${ }^{3}$ Université Lyon 1, LIRIS, CNRS5205, F-69622, Villeurbanne, France

${ }^{4}$ University of Geneva \& Distance Learning University Switzerland

*Corresponding author:

Elise Lavoué

iaelyon School of Management

Université Jean Moulin Lyon 3

$1 \mathrm{C}$ avenue des Frères Lumière

CS 78242 - 69372 Lyon Cedex 08

France

Elise.Lavoue@univ-lyon3.fr

\begin{abstract}
This paper studies learners' emotion awareness in university level academic contexts as a first step to help learners regulate their emotions. Existing emotion awareness tools offer little information on learners' emotions and their antecedents. This study created an emotion-reporting grid for university students based on the emotions they experienced daily. Students were interviewed based on their selfreported grid. A quantitative descriptive analysis of these retrospective interviews was conducted based on Pekrun's control-value theory of achievement emotions. Student transcripts were analyzed based on the focus of their emotions (retrospective, activity, or prospective), the causes they attribute to their emotions (agent or external circumstances) and how they appraised the situation in which they experienced the emotions (value and control). We discuss the results with regard to the types of emotion-oriented and appraisal-oriented regulation strategies used in learning contexts and draw implications for the design of emotion awareness tools to support emotion regulation processes.
\end{abstract}

\section{Keywords}

Emotion awareness tool, Emotion regulation, Appraisal regulation, Causal attributions, Academic context, Quantitative descriptive study

\section{Introduction}

Empirical studies have shown that learners' emotions have a major impact on learning processes and outcomes (Pekrun, Lichtenfeld, Marsh, Murayama, \& Goetz, 2017; Valiente, Swanson, \& Eisenberg, 2012). Emotions affect the cognitive, motivational, and regulatory processes mediating learning and achievement (Pekrun, 2006). In learning contexts, emotions have the function of indicating the presence of important, difficult, or 
complex aspects of the task that require attention and sustained effort (Boekaerts, 2010). Positive emotions such as enjoyment are generally assumed to facilitate students' selfregulation of learning, while negative emotions such as anxiety may induce reliance on external guidance (Wolters, 2003). Emotions can also impact students' interest and motivation to learn: positive emotions can enhance intrinsic motivation, whereas negative emotions can lead to a low level of interest (Pekrun, 2014). When either positive or negative emotions are not directly related to the learning task, they can consume cognitive resources necessary for task completion and can therefore impair cognitive performance (Meinhardt \& Pekrun, 2003).

Due to the critical role emotions play in learning and academic achievement, there is a need to provide learners with tools that raise their awareness of their emotions so they can regulate them when needed. Emotional awareness refers to the ability to perceive, identify, and understand emotions (Boden \& Thompson, 2015). It is considered as one of the selfobservation processes that occur in the monitoring phase of self-regulated learning (Pintrich, 2000) which is an important prelude to attempts to control and regulate emotions (Boden \& Thompson, 2015). Emotional information may also provide additional insight to enhance student learning (Linnenbrink-Garcia, Patall, \& Pekrun, 2016). Understanding the extent to which and how students are consciously aware of the emotions they are experiencing during learning is a necessary step towards designing tools to improve emotion regulation. Although a great deal of research has focused on emotions experienced in academic achievement contexts (Pekrun, 2006; Pekrun, Elliot, \& Maier, 2009), there is little literature that pertains to learners' awareness of their emotions in authentic learning situations. As a consequence, very few tools are dedicated to helping learners work on and with their emotions in the context of academic situations (Lavoué, Molinari, Prié, \& Khezami, 2015). Most of emotion awareness tools display learners' emotions without information that could help them understand the situations that provoked these emotions (Leony, Muñoz-Merino, Pardo, \& Delgado Kloos, 2013).

Thus, the following overarching question, undergirded in the aforementioned gap in the literature, motivates the present work: what emotions are learners consciously aware of in academic contexts and how do they perceive and understand these emotions? We conducted an ecological study on the types of emotions university students experience on a daily basis along with their understanding of their emotions and antecedents in academic contexts. A descriptive quantitative approach is used through self-reports and retrospective semi-structured interviews. The present study is intended to be contributory towards the Emoviz project, which aims to develop emotion reporting and visualization tools to help learners regulate their learning in academic contexts. 
In the paper, we first discuss emotion regulation and emotion awareness to identify a theoretical framework that focuses on three dimensions of emotion awareness for emotion regulation: object focus, appraisals and causal attributions of emotions. We focus on emotion-oriented regulation and appraisal-oriented regulation as defined in the Pekrun's control-value theory of achievement emotions (Pekrun, 2006). The findings of the present study are intended to contribute to our understanding of learners' awareness of their own emotions and their antecedents in specific learning situations. We discuss the implications of the findings in regard to what emotional information should be displayed on emotion awareness tools to help students regulate their emotions and their antecedents. This study will lead to the design of emotional awareness tools that are tailored to support learners' emotion regulation processes in authentic learning situations.

\section{Related Work}

\subsection{Emotion Regulation in Academic Contexts}

Emotion regulation refers to attempts to influence which emotions one has, when one has them, and how one experiences or expresses these emotions (Gross, 1998). (Gross \& John, 2003) distinguish two kinds of emotion regulation strategies: those that are responsefocused (expressive suppression) or those that are antecedent-focused (reappraisal, distraction). Suppression aims at inhibiting the emotional expression of an emotion, reappraisal at reinterpreting the meaning of an event so as to modify its emotional impact, and distraction at shifting the attention away from the emotional source.

More recently, Gross (2008) proposes the Modal model to highlight five points at which individuals can regulate their emotions: 1) situation selection involves taking actions by selecting a situation that will give rise to the emotions one likes to have; 2) situation modification implies making efforts to modify the situation directly so as to alter its emotional impact; 3 ) attentional deployment refers to influencing emotions by redirecting attention within a given situation; 4) cognitive change refers to changing appraisals in a way that alters the situation's emotional significance; 5) response modulation refers to influencing one's physiological, experiential, or behavioural responses to an emotion provoking situation.

In academic contexts, the Pekrun's control-value theory (2006) underlines that emotions can be regulated a) by manipulating the characteristics of the learning situation that can impact the control-value appraisals (this is similar to the situation selection/modification strategies in the Gross model), b) by encouraging students to modify the way they appraise the task relevance as well as their control over the task (or appraisal-oriented regulation that 
may correspond to the cognitive change strategy in the Gross model), c) by targeting the emotional experience itself (e.g. emotion-oriented regulation that can reduce or manage the intensity of negative feelings and that may be compared to response modulation strategies in the Gross model), and d) by providing students with additional supports (e.g. training for updating specific knowledge and skills) needed to perform the task or to facilitate learning (problem-oriented regulation also comparable to the situation modification strategy in the Gross model).

Our study focuses on emotion regulation strategies that directly depend on students' awareness of their own emotions (emotion-oriented regulation (c)) and their antecedents (appraisal-oriented regulation (b)). We so aim to identify information that could help learners regulate their emotions in academic contexts. In next section, we examine the link between emotion regulation and emotion awareness.

\subsection{Emotion Awareness for Emotion Regulation}

A necessary condition for students to engage in emotion regulation is to become aware of the emotions that come up for them in learning settings. Emotion awareness is described as the attentional process by which individuals identify, explain and differentiate between their own emotions as well as the others' emotions (Rieffe, Oosterveld, Miers, Meerum Terwogt, \& Ly, 2008). Lane and Schwartz (1987) distinguished between preconscious (implicit) and conscious (explicit) levels of emotional awareness. On the one hand, preconscious awareness refers to the physical and behavioral components of emotions. For instance, individuals can be aware of bodily sensations they have in reaction to the situation without being able to connect these negative tensions to specific emotions. On the other hand, individuals are consciously aware of their emotions when they are able to put them into words. Moreover, conscious awareness may concern the verbal expression of a) one emotion at one time, b) a blend of emotions at one time or even c) different blends of self and others' emotions. It also concerns not only the identification of the different types of emotions that emerge during learning but also the understanding of the situation that cause these emotions. Finally, students can get involved in a conscious awareness process of their emotions either while performing the learning task (real-time awareness; see e.g. (Molinari, Chanel, Bétrancourt, Pun, \& Bozelle, 2013)) or after the task (retrospective awareness) as a necessary step before a self-reflection activity (i.e. the "thinking about learning and its associated emotions" process; see (Lavoué et al., 2015)).

Emotion awareness and emotion regulation are both considered as principles of emotional change (Greenberg, 2008), and are strongly related to each other. Research shows that information provided by emotional awareness influences the regulation process (Boden $\&$ Thompson, 2015). Subic-Wrana et al. (2014) pointed out that the conscious awareness of 
emotions is a precondition of using adaptive emotion regulation strategies such as reappraisal (cognitive change). With this background, one may therefore assume that improving students' awareness of their emotions and their antecedents can help them regulate them, which can have positive impacts on their learning performances and outcomes. In next section, we propose a theoretical framework to examine information students need to be aware of to be able to regulate their emotions and appraisals.

\section{Theoretical Framework}

Our study focuses on emotion-oriented regulation and appraisal-oriented regulation to identify information that could help learners regulate their emotions in academic contexts. We rely on Pekrun's control-value theory (Pekrun, 2006) to identify three dimensions of emotion awareness for such emotion regulation processes: object focus, appraisal and causal attribution. In this section, we discuss each dimension and present the characteristics we examine in our study.

\subsection{Object Focus}

When discussing emotion-oriented regulation, the control-value theory differentiates emotions based on their object focus: a) activity emotions which pertain to the ongoing learning activities and b) outcome emotions which pertain to the outcomes of these activities (Pekrun, Elliot, \& Maier, 2006; Pekrun, Goetz, Titz, \& Perry, 2002). Moreover, two types of outcome emotions can be distinguished: a) prospective (anticipatory) emotions related to the outcome of ongoing or future activities (e.g., hope for success) and b) retrospective emotions related to the outcome of past activities (e.g., pride or shame experienced after feedback of achievement).

Encouraging students to identify whether their positive or negative emotions relate either to the activity or its outcomes may be viewed as a first step toward emotion-oriented regulation (Pekrun, 2006). For instance, it would be helpful for students to understand that the anxiety they feel while learning is actually an outcome anxiety (anxiety of potential failures) and that experiencing such a negative emotion as a result of too much attention on outcomes could be detrimental to learning.

\subsection{Appraisals}

Emotions can be considered as the result of an appraisal process (Scherer, Schorr, \& Johnstone, 2001); individuals have an emotion because of something or because of someone, and only when the event is appraised as significant (Sander, Grandjean, \& Scherer, 2005; Gross, 2015); it is significant when it is beneficial or harmful to one's well-being or when it 
matches or mismatches one's goals, needs, and values. The control-value theory (Pekrun, 2006) assumes that two types of appraisals, control and value, are critical for achievement emotions. Subjective value is defined as "perceived valences of actions and outcomes" (p. 317) and subjective control refers to the "perceived causal influence of an agent over actions and outcomes" (p. 317). Learners may have negative emotions if they perceive their level of control as low, and positive emotions if they perceive their level of control as high. They also may have negative emotions if their perceived values for the actions and outcomes are low, and conversely, they may have positive emotions if their perceived values are high. For example, this theory predicts that learners will experience enjoyment when they perceive themselves as being in control of the task and when they find the task to be of high interest.

If we refer to the appraisal-oriented regulation of academic emotions in Pekrun's control-value theory (2006), one may assume that students could benefit from being aware of the antecedents of their emotions as this would help them to reappraise the situation, that is, to positively change their initial perceptions of control over task and task value. Some studies have provided evidence that reappraisal leads to decreased negative emotion experience and expressive behavior (Dandoy \& Goldstein, 1990; Gross, 1998).

\subsection{Causal Attributions}

In this study, we also address the causal attributions learners provide for emotions experienced in specific situations, considered as a part of control appraisal in Pekrun's control-value theory (2006). According to Scherer et al. (2001), learners' first attempt to attribute the causes of an event to the agent that was responsible for its occurrence, or in the absence of an agent emotions are attributed to external circumstances (e.g., an upcoming exam). In the context of learning activities, we distinguish between three agents: the self, others, and the group (including the self) that refer to three kinds of regulation processes, respectively self-regulation, co-regulation, and shared regulation (Lajoie, Lee, Bassiri, CruzPanesso, Kazemitabar, Poitras, Hmelo-Silver, Wiseman, Chan, Lu, 2015).

Regarding the first step of emotion regulation in the Pekrun's control-value theory (2006), i.e. manipulating the characteristics of the learning situation, we posit that students should be aware of whether the emotion was caused by an external situation or by an agent before they can change a situation. On the one hand, making students aware of emotions that were caused by themselves could enable them to self-regulate (Paris \& Paris, 2001; Pintrich, 2004) by taking more control over a situation they can change. On the other hand, making students aware that emotions were caused by others or the group could influence their social relationships within the learning group and the way they regulate their emotions within the group (namely shared regulation (Hadwin et al., 2011)) or with their peers (namely coregulation (Hadwin, Järvelä, \& Miller, 2011; Jarvela \& Hadwin, 2013; Volet \& Vauras, 
2013)) when conducting group activities. Finally, students can learn how to recognize external circumstances that generate negative emotions and select situations accordingly.

To summarize, Figure 1 represents our theoretical framework that specifies three dimensions of emotion awareness that can support students' emotions and appraisals regulation: object focus (retrospective, activity or prospective), situation appraisal (subjective control and subjective value) and causal attribution (agents or external circumstances). Awareness of emotions and their object focus can support emotion-oriented regulation, while awareness of antecedents of emotions (appraisals and causal attributions) can support appraisal-oriented regulation.

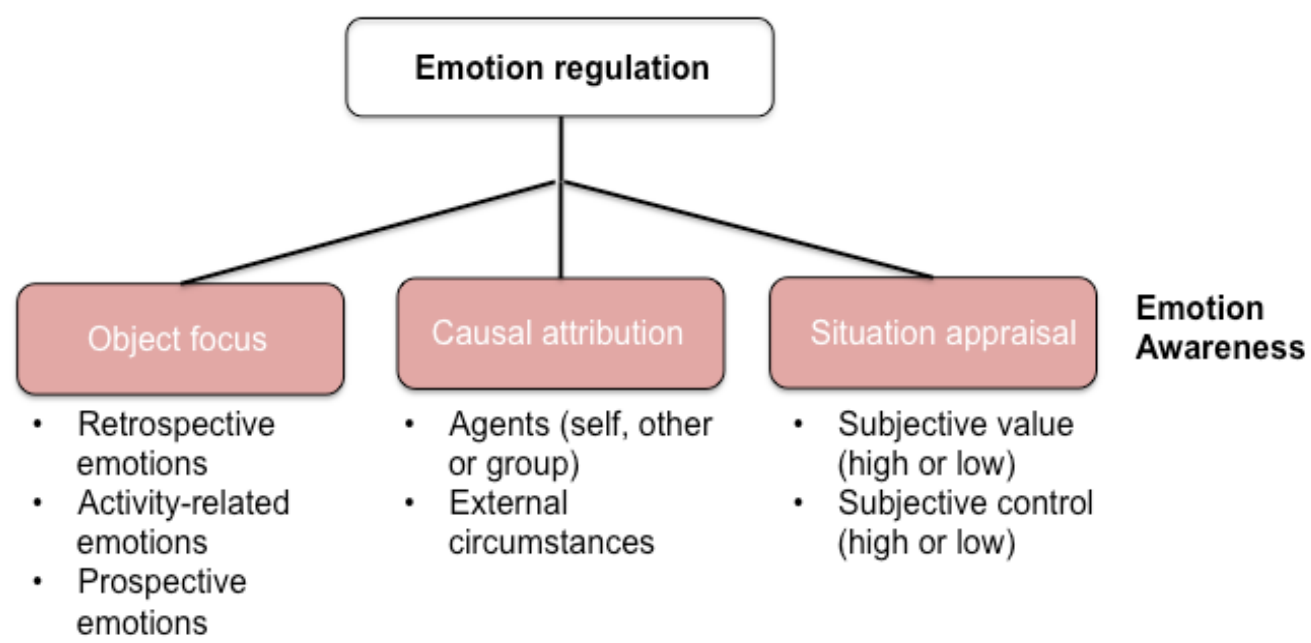

Figure 1. Three dimensions of Emotion Awareness that support Emotion Regulation: Object Focus, Causal Attribution, and Situation Appraisal.

\section{The Present Study: Research Questions and Methods}

\subsection{Research Questions}

In the present study, we investigate conscious emotion awareness by examining the object focus, the causal attributions and the appraisals of learners' emotions in an academic context. Our research questions are as follows:

1. What type of emotions are students able to verbally express in a retrospective awareness phase?

2. What is the perceived focus of these emotions? In other words, do students report emotions related to past activities (retrospective emotions), on-going activities (activity-related emotions), or outcomes of ongoing or future activities (prospective emotions)? 
3. What is the range of causes expressed by students regarding the emotions they report? Do the self-reported emotions emerge during events caused by agents (self, other, or group) or by external circumstances?

4. How do students appraise the situation in which they experience emotions? More specifically, what subjective value and subjective control is perceived by students when reporting the emotions they felt in specific contexts?

5. What is the relationship between the emotion focus and the perceived causes of emotions?

\subsection{Methods}

\subsubsection{Methodological choices}

Data collected on user emotions can be grouped into three categories (Cernea \& Kerren, 2015): perception-based estimations, physiological estimations and subjective feelings. Perception-based estimations consist in recognizing emotions from facial expressions, voice and body movements. Physiological measures of emotions are performed using devices installed on the human body and focus on the subconscious emotional responses (e.g. heartbeat, blood pressure and sweating). Subjective feelings consist of selfreports of emotions. Perception-based and physiological measures of emotions have an objective aspect which is interesting, but are more suited to laboratory conditions. Furthermore, such measures inform on the preconscious level of emotion awareness defined by Lane and Schwartz (1987), but not specifically on emotions learners are consciously aware of.

We focus on the self-report of discrete emotions, which is a less technologydependent method, and more easily deployed remotely (Cernea \& Kerren, 2015). There are two commonly used measures of emotion awareness: the Emotion Awareness Questionnaire (EAQ; Rieffe et al., 2008) and the Levels of Emotional Awareness Scale (LEAS; Lane, Quinlan, Schwartz, Walker, \& Zeitlin, 1990). Individual differences in the use of emotion regulation strategies can also be assessed, using the Emotion Regulation Questionnaire (Gross \& John, 2003). These questionnaires are well suited to evaluate learners' emotion awareness and regulation strategies. However, they are not designed for measuring emotions learners can verbally express in ecological conditions, meaning they are consciously aware of these emotions.

In the present study, we use self-report method for measuring conscious emotions with retrospective interviews. This method for measuring emotions follows from research that utilizes ecological momentary assessments (Tong et al., 2007; Versluis, Verkuil, Lane, 
Hagemann, Thayer, \& Brosschot, 2018)) and experience sampling methods (Goetz, Frenzel, Stoeger, \& Hall, 2010). Students' perceptions of their emotions were collected on a daily basis over a period of one week. We combine this assessment with retrospective interviews with students to provide more context about student's own perception and understanding of their past conscious emotions.

\subsubsection{Participants}

Participants were 11 ( 8 female, 3 male; 3 Caucasian, 8 Asian; and, average age was 24 years) undergraduate and graduate science, technology, engineering and mathematics (STEM) students from a large North American university. The samples are from a range of students in different disciplines and different classes. The study was reviewed and approved by an institutional review board (IRB).

\subsubsection{Material}

Participants were provided with two documents: a) a demographics questionnaire, which included questions related to their age, gender, and academic history; b) an Emotion Recording Grid (see Appendix A) that was designed for this study. This pre-structured grid leads participants to report their emotions along two axes: the day of the week on the abscissa and the time slot on the ordinate. Four time slots were identified: from 0am to 6am; from $6 \mathrm{am}$ to $12 \mathrm{pm}$; from $12 \mathrm{pm}$ to $6 \mathrm{pm}$; from $6 \mathrm{pm}$ to $0 \mathrm{am}$. Information was also provided in the bottom of the grid to incite learners to report it in the grid in a structured manner: the settings (individual or in a group; at home, school or professional) and emotions. A list of nine different academic-related emotions based on (D'Mello, Lehman, Pekrun, \& Graesser, 2014), i.e. anxiety, boredom, confusion, curiosity, delight, engagement, frustration, surprise, and neutral, was given to participants to help them report what they felt. Academic emotions are emotions students experience in academic situations (Pekrun, 2016). Rather than using Pekrun's achievement emotions 13-item questionnaire, we chose D'Mello et al.'s (2014) scale since 1) it was shorter and so easier to reflect on when filling the grid, 2) it was related to emotions in academic contexts, not just achievement contexts, and 3) it considered the same number of positive and negative emotions, allowing the comparison of the type of emotions reported by the students.

\subsubsection{Procedure}

The demographics questionnaire and the Emotion Recording Grid were sent to the participants by email. Participants were instructed to report only their academic-related emotions. Participants filled in the grid at their own convenience over a complete week; 
participants were free to report several emotions related to a same event and any contextual information they may need to recall their emotions during retrospective interviews. They could report their emotions once or several times per day. This reporting phase occurred at the middle of the second semester, between the end of February 2016 and March 2016.

After completing the weekly emotion grid, participants brought their grid to the researchers' lab where they were asked to explain their thoughts about the emotions they reported on the grid. These retrospective interviews were conducted by the same interviewer and audio-recorded. The interviews referred to the emotions reported in the grid. We asked participants to describe each emotion or group of emotions reported at a given moment, the situation (i.e. alone or in-group, in-class or at home, what they were thinking about), what the emotions were connected to and the causes. Each interview session lasted about half an hour. Audio transcriptions of the interviews were transcribed verbatim with approximately 12 pages overall per session. Students were free to report their emotions using the grid when they experienced rather than being directed to report at exact times.

\subsubsection{Analysis Method}

Given the small sample size overall $(N=11)$, we used a quantitative descriptive analysis that integrates qualitative and quantitative data to answer the five research questions. Based on our theoretical framework, we analyzed the emotions expressed by students during the interviews, their focus and their antecedents. We aim at identifying what they are retrospectively aware of. The analysis process was as follows.

Each interview transcription was fully coded by two independent coders who were trained by the principal investigator. Units of analysis were identified by the principal investigator and coders attributed the best codes that would describe the unit. A unit is an emotion described by the participant that was in accordance with D'Mello et al.'s (2014) academic-related emotions list. Each unit (emotion) was associated with an episode reported by the participant (e.g. a specific course or a group work), multiple units may be associated with the same episode. In total 190 units of analysis were derived from the transcript data.

A theory-driven coding scheme (see Appendix B) was developed to analyze the transcriptions based on our five research questions. The coding scheme was refined in multiple rounds to ensure integrity and clarity, according to the following steps: 1) we identified emotions reported by the participants as well as the setting in which they occurred (individual or group setting where social interactions occurred between students and/or between teachers and students); 2) we analyzed the object focus of each emotion: the ongoing learning activity (activity-related emotion), past activities or their outcomes (retrospective emotions), or future activities or their outcomes (prospective emotions); 3) we analyzed the causes expressed by the participant: the student's own behavior (self), the 
behavior of another person (other), a group of persons (group) or external circumstances; 4) we analyzed the way students appraised the situation in which they reported experiencing emotions: the perceived control over the activity (low or high) and the perceived value (positive or negative) for the activity; 5) finally, the analysis of object-focus and causalities allowed us to answer our fifth question on the relationship between focus and causality. The inter-rater reliability between coders was calculated as $89.27 \%$ using the Pearson correlation coefficient.

\section{Results}

\subsection{Students' Emotions}

Table 1 presents the overall frequency and valence of emotions reported by students during the interviews. Overall, students expressed more negative emotions than positive emotions (31.1\%). Regarding negative emotions, the most frequently reported emotions are anxiety, frustration, and boredom. Regarding positive emotions, curiosity is reported the most frequently followed by delight and engagement. Surprise was mentioned the least. Students reported being in a neutral emotional state with the same frequency as curiosity.

The situations in which students reported experiencing emotions were mainly individual academic settings (85.3\%) versus group settings (14.7\%). Positive emotions were expressed 0.67 times lower (33\%) than negative emotions (48.9\%) in individual settings. Moreover positive emotions were reported 0.5 times lower (4.8\%) than negative emotions $(9.5 \%)$ in group settings. This indicates that most of emotions felt in individual and group settings are negative, and that students tend to feel a bit more positive in group settings. In contrast, all neutral emotional states were reported in individual settings, suggesting that group settings are more "emotional" than individual settings.

Table 1. Number, Percentage and Valence (Positive or Negative) of Emotions per Setting (Individual or Group)

\begin{tabular}{|c|c|c|c|c|c|c|c|}
\hline & \multicolumn{2}{|c|}{ Individual } & \multicolumn{2}{|c|}{ Group } & \multicolumn{2}{|c|}{ Total } & \multirow{2}{*}{$\begin{array}{c}\text { Valence } \\
\text { of } \\
\text { emotion }\end{array}$} \\
\hline & No. & $\%$ & No. & $\%$ & No. & $\%$ & \\
\hline Anxiety & 31 & $16.3 \%$ & 6 & $3.2 \%$ & 37 & $19.5 \%$ & Negative \\
\hline Frustration & 26 & $13.7 \%$ & 4 & $2.1 \%$ & 30 & $15.8 \%$ & Negative \\
\hline Boredom & 23 & $12.1 \%$ & 5 & $2.6 \%$ & 28 & $14.7 \%$ & Negative \\
\hline
\end{tabular}




\begin{tabular}{lccccccc} 
Confusion & 13 & $6.8 \%$ & 3 & $1.6 \%$ & 16 & $8.4 \%$ & Negative \\
Curiosity & 17 & $8.9 \%$ & 3 & $1.6 \%$ & 20 & $10.5 \%$ & Positive \\
Delight & 13 & $6.8 \%$ & 3 & $1.6 \%$ & 16 & $8.4 \%$ & Positive \\
Engagement & 13 & $6.8 \%$ & 3 & $1.6 \%$ & 16 & $8.4 \%$ & Positive \\
Surprise & 7 & $3.7 \%$ & 0 & $0.0 \%$ & 7 & $3.7 \%$ & Positive \\
Neutral & 19 & $10.0 \%$ & 1 & $0.5 \%$ & 20 & $10.5 \%$ & Neutral \\
\hline Total & $\mathbf{1 6 2}$ & $\mathbf{8 5 . 3 \%}$ & $\mathbf{2 8}$ & $\mathbf{1 4 . 7 \%}$ & $\mathbf{1 9 0}$ & $\mathbf{1 0 0 . 0 \%}$ & \\
\hline
\end{tabular}

\subsection{Emotions and Object Focus}

Table 2 documents the nature of the object focus indicating that activity emotions (i.e. emotions experienced during the course they were attending or the activity they were carrying out) were expressed almost twice as often (65.1\%) as outcome emotions (34.9\%). Regarding outcome emotions, they reported more prospective (20.5\%) than retrospective emotions (14.4\%). Negative activity emotions were reported 1.48 times more frequently $(32.8 \%)$ than positive activity emotions (22.1\%). Negative outcome emotions were reported 3.10 times more frequently (26.7\%) than positive outcome emotions (8.2\%). These findings suggest that students responded more negatively when focusing on their past or future learning activities and outcomes. The ratio between negative and positive emotions (negative emotions $>$ positive emotions) was also higher for prospective emotions (4.00) than for retrospective emotions (2.51), which suggests that students experienced a more negative emotional state when anticipating the activity and their performance. Finally, neutral emotional states were only reported in the activity-related category, suggesting that thinking about past or future activities and outcomes induces more emotions than thinking about the activity.

Table 2. Percentage of Emotions per Valence (Positive, Negative, Neutral) and Object-Focus (Retrospective, Activity, Prospective)

\begin{tabular}{lcccc}
\hline Valence of emotion & $\mathbf{\%}$ & Retrospective & Activity & Prospective \\
\hline Positive & $30.3 \%$ & $4.1 \%$ & $22.1 \%$ & $4.1 \%$ \\
Negative & $59.5 \%$ & $10.3 \%$ & $32.8 \%$ & $16.4 \%$ \\
Neutral & $10.3 \%$ & $0.0 \%$ & $10.3 \%$ & $0.0 \%$
\end{tabular}




\begin{tabular}{lcccc} 
Total (\%) & $\mathbf{1 0 0 . 0 \%}$ & $\mathbf{1 4 . 4 \%}$ & $\mathbf{6 5 . 1 \%}$ & $\mathbf{2 0 . 5 \%}$ \\
Total (No.) & 195 & 28 & 127 & 40 \\
\hline
\end{tabular}

The two excerpts below show examples of (a) negative and (b) positive activityrelated emotions:

a. "I had a presentation on Monday, but because I was stopped to learn about something, I was frustrated ...!". Here the negative activity emotion is "frustration".

b. "Later that night I studied again and I guess I felt engaged with the material. I actually understood it... yeah that night, I felt like I was going through the work at a decent rate, so I was happy about that!" Here the positive emotions are "engagement" and "delight".

\subsection{Emotions and Causal Attributions}

Students attribute their emotions almost equally to themselves or external circumstances (see Table 3). The low number of group academic situations (i.e., situations with social interactions) reported by the students (14.7\% in Table 1) can explain the low attribution to the group or to others. Nevertheless, we observe that students attributed their emotions to the group or others in $64.3 \%$ of the group situations, with a majority to the group (39.3\%), and less to others (25.0\%). Regarding the type of emotions, students attribute their positive and neutral emotions mainly to themselves (respectively $17.8 \%$ and $6.8 \%$ ), whereas they mainly attribute their negative emotions to external circumstances (29.3\%). Moreover, the ratio of negative and positive emotions (negative emotions $>$ positive emotions) was higher for the others (3.63) than for the group (1.48) and the self (1.15) as causes of emotions. This suggests that students perceived the others as a potential source of negative emotions.

Table 3. Percentage of Emotions per Valence (Positive, Negative, Neutral) and Agent (Self, Others, Group) or External Circumstances

\begin{tabular}{lccccc}
\hline $\begin{array}{l}\text { Valence of } \\
\text { emotions }\end{array}$ & \% & Self & Others & Group & Circumstances \\
\hline Positive & $30.9 \%$ & $17.8 \%$ & $1.6 \%$ & $2.1 \%$ & $9.4 \%$ \\
Negative & $58.6 \%$ & $20.4 \%$ & $5.8 \%$ & $3.1 \%$ & $29.3 \%$ \\
Neutral & $10.5 \%$ & $6.8 \%$ & $0.0 \%$ & $0.5 \%$ & $3.1 \%$ \\
Total (\%) & $\mathbf{1 0 0 . 0 \%}$ & $\mathbf{4 5 . 0 \%}$ & $\mathbf{7 . 3 \%}$ & $\mathbf{5 . 8 \%}$ & $\mathbf{4 1 . 9 \%}$
\end{tabular}


Below are excerpts of causal attributions of (a) positive emotion to self and (b) negative emotions to external circumstances, and also an example of (c) attributing causes of negative emotions to the group:

a. "That night I studied again and I guess I felt engaged with the material. I actually understood it" Here the positive emotion is "engagement".

b. "I was a bit anxious cuz I had to do a lot of things at the same time while being abroad." Here the negative emotion is "anxiety".

c. "Design project, frustration, group work... at some point I met with my group members to like, we had to work together but we keep starting at the same point for a few days, I got bored, so I didn't do academic stuff because I was tired." Here the negative emotion is "boredom".

\subsection{Emotions and Appraisals}

The majority of the situations students reported were associated with low control (67.6\%, see Table 4). We also observe that a high number of negative emotions were associated with low perceived control (46.9\%). High control was rather equally associated with positive and negative emotions. A high number of situations $(N=45)$ were not associated with a specific level of control (high or low).

Table 4. Percentage of Emotions Valence (Positive, Negative, Neutral) and Level of Control (High or Low)

\begin{tabular}{lcccc}
\hline Valence of emotion & No. & \% & High Control & Low Control \\
\hline Positive & 47 & $32.4 \%$ & $16.6 \%$ & $15.9 \%$ \\
Negative & 89 & $61.4 \%$ & $14.5 \%$ & $46.9 \%$ \\
Neutral & 9 & $6,2 \%$ & $1.4 \%$ & $4.8 \%$ \\
Total & $\mathbf{1 4 5}$ & $\mathbf{1 0 0 . 0 \%}$ & $\mathbf{3 2 . 4 \%}$ & $\mathbf{6 7 . 6 \%}$ \\
\hline
\end{tabular}

We provide an excerpt of an interview showing low control associated with negative emotions: "I was studying for physiology but I had anxiety because I had a midterm exam coming up soon." Here the negative emotion is "anxiety".

Finally, we observe in Table 5 that students mainly reported academic situations that had a high subjective value for them (77.0\%), and only a low number of situations were associated with a low perceived value $(23.0 \%)$. Compared to the valence of emotions 
reported by the students, the results show that students were more likely to report negative emotions in high-valued academic situations (46.7\%) than in low-valued situations (15.2\%). We also observe that almost all positive emotions were associated with situations with a high perceived value (30.3\% against 3.6\% for low-valued settings). At the same time, students reported mainly low importance situations that provoked negative emotions (in comparison with positive and neutral emotions).

Table 5. Percentage of Emotions per Valence (Positive, Negative, Neutral) and Value (High or Low)

\begin{tabular}{lcccc}
\hline $\begin{array}{l}\text { Type of } \\
\text { emotion }\end{array}$ & No. & $\%$ & High Value & Low Value \\
\hline Positive & 56 & $33.9 \%$ & $30.3 \%$ & $3.6 \%$ \\
Negative & 102 & $61.8 \%$ & $46.7 \%$ & $15.2 \%$ \\
Neutral & 7 & $4.2 \%$ & $0.0 \%$ & $4.2 \%$ \\
Total & 165 & $\mathbf{1 0 0 . 0 \%}$ & $\mathbf{7 7 . 0 \%}$ & $\mathbf{2 3 . 0 \%}$ \\
\hline
\end{tabular}

Examples of reporting negative emotions in (a) important and (b) low-importance academic situations are as follows:

a. "And then I planned to do something about the thesis, but unfortunately my plan didn't work. All the time when I was thinking about my thesis, I was frustrated, and every emotion I had was on that thing." Here the negative emotion is "frustration".

b. "It was in the class, the class was like boring." Here the negative emotion is "boredom"

\subsection{Object Focus and Causal Attributions}

We were also interested in the relationship between the object focus and the cause (agents or external circumstances) of emotions. We observe (see Table 6) that emotions provoked by others or the group are mainly activity-related, meaning that outcome emotions were reported only when they were provoked by students themselves or external circumstances. Self and external circumstances rather equally provoked retrospective outcome emotions, whereas prospective outcome emotions were mainly associated with external circumstances. Activity-related emotions were mainly provoked by self, followed by external circumstances.

Table 6. Percentage of Emotions per Object-Focus (Retrospective, Activity or Prospective) and Agent (Self, Others, Group) or External Circumstances 


\begin{tabular}{lcccc}
\hline \multicolumn{1}{c}{ Object Focus } & \multicolumn{4}{c}{ Agent } \\
\cline { 2 - 5 } & Self & Others & Group & Circumstances \\
Retrospective & $6.1 \%$ & $1.0 \%$ & $0.0 \%$ & $7.1 \%$ \\
Activity & $34.5 \%$ & $6.1 \%$ & $5.6 \%$ & $18.8 \%$ \\
Prospective & $5.6 \%$ & $1.0 \%$ & $0.0 \%$ & $14.2 \%$ \\
\hline
\end{tabular}

The following excerpts provide examples of (a) prospective and (b) retrospective emotions caused by the self or external circumstances.

a. "Exactly on the same day, I figured out I have a presentation on Thursday. I didn't know before. So it's kind of really, okay I have a presentation (M: okay), I have to prepare for it and I had anxiety." Here the prospective emotion is "anxiety".

b. 'I was frustrated about the marks. It's the easiest subject but I didn't do very good." Here the retrospective emotion is "frustration".

Finally, we examined the relationship between the object focus of emotions reported by the students and their subjective appraisal of the academic situation (see Table 7). Retrospective and prospective emotions were associated only with high-value academic situations (i.e., that were positively perceived by students). These emotions were also mainly associated with situations in which students were perceived as having low control. Activityrelated emotions were appraised 1.84 times more frequently as positive (39.8\%) than negative (21.6\%) and 1.81 times more frequently as low-controlled (38.4\%) than highcontrolled (21.2\%). Students reported activity emotions experienced in situations appraised as important and in which they also had a low control.

Table 7. Percentage of Emotions per Object-Focus (Retrospective, Activity, Prospective), Value (High or Low) and Control (High or Low)

\begin{tabular}{ccccc}
\hline Object Focus & \multicolumn{2}{c}{ Value } & \multicolumn{2}{c}{ Control } \\
\cline { 2 - 5 } & High & Low & High & Low \\
\hline Retrospective & $15.8 \%$ & $0.6 \%$ & $6.6 \%$ & $10.6 \%$ \\
Activity & $39.8 \%$ & $21.6 \%$ & $21.2 \%$ & $38.4 \%$ \\
Prospective & $22.2 \%$ & $0.0 \%$ & $5.3 \%$ & $17.9 \%$ \\
\hline
\end{tabular}




\section{Discussion}

\subsection{Main Findings}

This study brings new insights about students' conscious awareness of their own emotions and their antecedents in academic contexts. In particular, we focused on emotion object focus, situation appraisal and causal attributions. We summarize our findings below. Types of emotions. Our findings revealed that students expressed mainly negative emotions (anxiety, frustration, and boredom). These expressed negative emotions were related to both individual and group learning experiences. It could suggest that positive emotions experienced in academic situations are less frequently remembered, that is students are more consciously aware of their negative emotions than the positive ones. This is consistent with the memory-experience gap, a memory bias usually observed for unpleasant emotions that leads individuals to amplify the intensity of experienced negative emotions in retrospective evaluations (Miron-Shatz, Stone, \& Kahneman, 2009).

Perceived focus of emotions. Our study reveals three major findings regarding the focus of emotions. First, activity emotions were reported most frequently, implying that students are mainly aware of emotions related to the task they carry out, rather than to emotions related to outcomes of past or future activities. Second, students reported no neutral retrospective and prospective emotional states. This finding suggests that students' reflection on outcomes of past or future activities may provoke either positive or negative emotions, but not a neutral state. Third, the results also show that retrospective and prospective emotions are mainly negative, implying that it could be difficult for students to reflect on the outcome of their past or future activities in a positive way.

Perceived causes of emotions. First, based on the findings of our study, students associate their emotions almost equally to themselves or external circumstances (e.g., exams, deadlines) and rarely to other students. Second, regarding the valence of emotions, students associate their positive emotions and neutral emotional states mainly to themselves, whereas they mainly associate their negative emotions to external circumstances. These findings suggest that positive emotions are associated with situations where students feel in control and can "act" on their emotions, whereas negative emotions are associated with situations where they do not feel in control and they depend on external contingences.

Perceived appraisal of situations. Regarding the perceived control of the situations in which students experience emotions, we first identify that they report mainly emotions associated with a low control, with a high percentage of negative emotions. This result is in line with studies that show that emotions associated with a low control provoke mainly negative emotions, such as anxiety and frustration (Pekrun, 2006). Second, we also observe 
that a high number of situations are not associated with a specific level of control (high or low). We deduce that perceived control is an appraisal dimension that is not frequently used by students to explain their emotions, meaning that they may have difficulties in assessing their level of control over learning tasks.

Concerning the perceived value of the situation, students mainly reported emotions in important academic situations, i.e. with a high subjective value. These situations were mainly associated with negative emotions, which is consistent with the high percentage of negative emotions reported by students during interviews (e.g., frustration), and the low number of positive emotions, such as delight and engagement. We also observe that all positive emotions were associated with high-perceived valued situations. This finding suggests that students are mainly aware of academic situations that were of importance for them, whether they provoked positive or negative emotions.

Association between emotion focus and perceived causes of emotions. Our study reveals two major findings regarding the association between the perceived focus of emotions and their causes. First, emotions provoked by others or the group were only related to the activity. It suggests that students may be aware of retrospective and prospective emotions only when they were provoked by self or external circumstances. Another hypothesis is that students may be more concerned with themselves and external circumstances such as deadlines and exams. Second, retrospective and prospective emotions were associated only with positive value, mainly when students had a low control. This finding suggests that students may be aware of prospective or retrospective emotions only when they relate to important situations they cannot easily regulate due to a low control.

\subsection{Limitations of the Study}

This is an exploratory descriptive quantitative study with a small number of participants from one university, and more research is necessary to confirm our results in other contexts. However, the descriptive results are informative in that they reveal the types of emotions, focus, appraisals and causal attributions made by students in academic settings. This exploratory study assists in drawing new lines of research for the design of emotion awareness tools.

Another limitation may be due to the constraint the participants had in reporting emotions from a specific list. Students may have reported other emotions if the choices were less constrained. Nonetheless, the list of emotions helped students to verbally express specific emotions during retrospective interviews, facilitating their awareness of emotions.

Unfortunately, the participants only experienced a few group situations during the week they reported their emotions. This low occurrence of group situations may explain the low number of emotions provoked by others or by the group. We would like to conduct more 
experiments that include group situations to conduct a more in-depth analysis of the causalities expressed in individual and group situations.

Another limitation of this study is that the retrospective nature of the interview process may have made it difficult for participants to remember emotions they reported in the emotions reporting grid. Students may have failed to report the antecedents of their emotions either because they were not aware of the causes and/or appraisals when they felt them or because they did not remember them. This bias is limited by the fact that they could report contextual information in the grid associated to the emotions they felt during the week and use this information during the interviews. Nonetheless, we think it draws important future directions for studies on students' retrospective awareness of emotions and new methods have to be proposed to avoid this mixing.

\subsection{Implications for the Design of Emotion Awareness Tools}

Examining students' awareness of their emotions and their antecedents brings insights on what emotional information learners may need to regulate their emotions. To our knowledge, our study is the first to address this research issue in authentic settings. We discuss in this section implications of our findings for the design of Emotion Awareness Tools (EAT) to support emotion-oriented regulation and appraisal-oriented regulation as defined in the Gross model. Emotion Awareness Tools can be defined as tools that display information on own' own or partners' emotions, circumstances and antecedents.

\subsubsection{Emotion Awareness Tools to Support Emotion-oriented Regulation}

As a third step of the Gross's regulation model, emotion-oriented regulation consists in targeting the emotional experience itself, by reducing or managing negative emotions. In an academic context, most existing EAT provide learners with basic representations of emotions through textual lists of emotions (Molinari et al., 2013; Ruiz et al., 2016), colors (Tian, Zhang, Li, Zheng, \& Yang, 2011), valence and arousal dimensions (Cernea, Weber, Ebert, \& Kerren, 2013; McDuff, Karlson, Kapoor, Roseway, \& Czerwinski, 2012) or colored markers (Lavoué et al., 2015). In that way, EAT help learners be aware of their current emotions and they can be very useful as a first step toward emotion regulation. However, they are generally not designed to promote a specific kind of emotion (i.e. positive or negative). Furthermore, they do not provide an history of emotions felt in the past and so do not allow learners self-reflect retrospectively on their emotions.

In our study, we observed that students mainly report negative emotions in academic situations. Accordingly, and regarding the design of EAT, our findings suggest not only to show felt emotions but also to promote positive emotions that may be neglected by students. 
This could help learners remember and/or be aware of more positive emotions associated with academic situations; and so reduce the high level of anxiety, boredom, and frustration reported by students. Following this recommendation, we developed the EMODA dashboard that provides a timeline of emotions felt by students during synchronous online sessions (EzZaouia, \& Lavoué, 2017). We clearly distinguish negative and positive emotions with two colors (red and green) to highlight students' awareness of positive emotions felt in the past.

Existing EAT do not show learners the focus of their emotions, i.e. emotions related to the current activity or emotions associated to outcomes of past or future activities. In the current study, students report mainly activity-related emotions. We recommend EAT to promote the emotions that pertain to the outcomes of past, ongoing or future activities (Pekrun et al., 2006, 2002). Making students aware of the focus of their emotions could help them focus their attention on events that provoke more positive emotions, for instance remembering good marks that provoked delight rather than thinking of an exam that provoked anxiety. This information could be collected using prompts that ask students once or several times per day, or during particular activities, the emotions they feel and what they are thinking about. Then an EAT can provide students with this information by highlighting outcome emotions. As a first step toward such an EAT, we developed the Emoviz emotion annotation tools that allows students annotate their own or peers' documents while reading using emojis (Sun, Lavoué, Aritajati, Tabard, Rosson, 2019). We then plan to extract separately the different kinds of emotions regarding their object focus based on a semantic analysis of both texts and annotations.

\subsubsection{Emotion Awareness Tools to Support Appraisal-oriented Regulation}

Appraisal-oriented regulation can be supported by encouraging students to modify the way they appraise the task relevance as well as their control over the task (Gross, 2008). Currently, some complex affective awareness systems display emotions with information on the context in which users felt them. The most well-know is AffectAura (McDuff et al., 2012), a reflective tool that combines automatic labels for valence (negative, neutral, positive), arousal (low, high) and engagement (low, high) with contextual information like the user's calendar events, activity, location, files and application interactions at each hour. Another example is the MoodMap tool (Fessl, Rivera-Pelayo, Pammer, \& Braun, 2012) that enables users to note and review their own mood over time, and to obtain insight about team mood according to a given meeting and date. However, only few advanced visualizations of emotions are proposed in a learning context (Leony et al., 2013) and most of the research is dedicated to the teachers to monitor their learners. These systems provide teachers with information on the situational circumstances that provoke students' emotions and thus can help them regulate these situations. As also suggested by Ruiz et al. (2016) in their review of 
several emotional visualizations in the educational domain, information on the situational circumstances or the antecedents of the emotions could enrich the visualizations to help students reflect on their emotions. They so could learn how to recognize situations that provoke positive or negative emotions.

In our study, students mainly report academic situations with a low perceived control and a high perceived value that provoke negative emotions. EAT should help them identify the negative emotions they experienced in situations associated with a low level of control and the positive emotions in situations where they had a higher level of control. In that way, students can reappraise the value or the control they have for the situation. We could even imagine that they learn to recognize these learning situations and to manipulate their characteristics that can impact the control-value appraisals (Pekrun, 2006). EAT could also promote situations with a high control and a high value and associated positive emotions, such as enjoyment, to help learners recognize these situations and select them in the future. Of course, students may need guidance to identify the level of control they have on the learning situation as our study reveals that a high number of situations were not associated with a specific level of control. Guidance would also be needed to identify the characteristics of the situation the learners are able to change, for instance by inciting them start revisions early to be less anxious for an exam.

As a first step toward EAT to support appraisal regulation, we developed the EMODA emotional dashboard (Ez-Zaouia, \& Lavoué, 2017) that helps tutors monitor their learners by presenting information on the context associated with their emotions. We collect heterogeneous data, including automatically collected data (learners' emotions based on face recognition techniques, interaction traces with the videoconferencing environment and videos of the online interactions) and self-reported data before and after synchronous online sessions. Users can click on a specific emotion represented in a timeline to access the video of the episode during which the emotion was measured. This dashboard could be used by the learners themselves to support retrospective self-reflection on their emotions and the context associated to them (e.g. anxiety due to the course content, or delight due to the interaction with the tutor).

\section{Conclusions and Future Work}

This work is a first step toward the support of learners' emotion regulation to address the need for tailored emotion awareness tools. We focused our study on emotion-oriented and appraisal-oriented regulations to identify information that could help learners regulate their emotions in academic contexts. We relied on Pekrun's control-value theory of achievement emotions (2006) to distinguish three dimensions of emotion awareness: object 
focus, appraisal and causal attribution. We proposed a method to identify students' awareness of these emotional dimensions based on an emotions recording grid and retrospective interviews. Our findings show that students are less aware of situations in which they felt some kinds of emotions, foci and antecedents (i.e. outcomes emotions, emotions provoked by agents other than self, high control situations).

More data are needed to confirm these findings but they allowed us to suggest different ways emotion awareness tools can promote positive emotions felt regarding past, on-going and future learning situations and their outcomes to support emotion-oriented regulation. We also discussed how emotion awareness tools can display information that help students identify associations between their emotions and their antecedents, to be able to reappraise the learning situations, to manipulate their characteristics or even to avoid similar situations that provoked negative emotions.

Self-observation and awareness of emotions are self-regulatory strategies that are usually implemented in a deliberate and controlled way. The practice of such strategies can be experienced by students as "unpleasant and effortful" (Sokolowski, 1993 cited by Rheinberg, Vollmeyer, \& Rollett, 2000, p. 517); this would be especially the case for students with low self-regulatory competencies or for students who feel mainly negative emotions, for instance in a depressed emotional state. The limited working memory capacity should therefore be taken into account when designing awareness tools. The processing of awareness information about emotions should remain a secondary task and should not interfere with the cognitive demands of the learning task. Moreover, students need personalized guidance on how they can use emotional information. Such guidance could be brought either by a teacher or by the tool, and requires information on the learning situation and expected outcomes to allow personalization.

The next step towards the development of emotion awareness tools is to identify appropriate methods to collect and integrate information on students' emotion appraisal, object-focus and causes, either in real-time or retrospectively. Our current work is focused on emotion reporting tools that could be used in authentic settings to collect such data in real time, however it is challenging, as it requires a high level of reflection from the students. We believe that providing learners with relevant emotion visualization tools is a means to help them reflect on their emotions and report them, and ultimately help them regulate these emotions in academic settings.

\section{Acknowledgement}

Our research was conducted as part of the EmoViz project funded by the Région AuvergneRhône-Alpes. We thank the students who volunteered to participate to this study. 


\section{References}

Boden, M. T., \& Thompson, R. J. (2015). Facets of emotional awareness and associations with emotion regulation and depression. Emotion, 15(3), 399-410. http://dx.doi.org/10.1037/emo0000057

Boekaerts, M. (2010). The crucial role of motivation and emotion in classroom learning. In The nature of learning: Using research to inspire practice (pp. 91-111). Paris: OECD Publishing. http://dx.doi.org/10.1787/9789264086487-en

Bradley, M. M., \& Lang, P. J. (1994). Measuring emotion: The self-assessment manikin and the semantic differential. Journal of Behavior Therapy and Experimental Psychiatry, 25(1), 49-59. https://doi.org/10.1016/0005-7916(94)90063-9

Cernea, D., Ebert, A., \& Kerren, A. (2014). Visualizing group affective tone in collaborative scenarios. In Poster Abstracts of the Eurographics Conference on Visualization (EuroVis' 14) (p. 3). Swansea, Wales, UK.

Cernea, D., Weber, C., Ebert, A., \& Kerren, A. (2013). Emotion Scents - A method of representing user emotions on GUI widgets. In Proceedings of the SPIE 2013 Conference on Visualization and Data Analysis (VDA '13), Burlingame, CA, USA: SPIE. http://dx.doi.org/10.1117/12.2001261

Cernea, D., \& Kerren, A. (2015). A survey of technologies on the rise for emotion-enhanced interaction. Journal of Visual Languages \& Computing, 31, 70-86. https://doi.org/10.1016/j.jvlc.2015.10.001

Dandoy, A. C., \& Goldstein, A. G. (1990). The use of cognitive appraisal to reduce stress reactions: A replication. Journal of Social Behavior \& Personality, 5(4), 275-285.

D’Mello, S., Lehman, B., Pekrun, R., \& Graesser, A. (2014). Confusion can be beneficial for learning. Learning and Instruction, 29, 153-170. https://doi.org/10.1016/j.learninstruc.2012.05.003

Ez-Zaouia, M., \& Lavoué, E. (2017). EMODA: a tutor oriented multimodal and contextual emotional dashboard. In Proceedings of the Seventh International Learning Analytics \& Knowledge Conference (pp. 429-438). Vancouver, Canada. ACM. https://doi.org/10.1145/3027385.3027434

Fessl, A., Rivera-Pelayo, V., Pammer, V., \& Braun, S. (2012). Mood tracking in virtual meetings. In 21 st century learning for 21st century skills (Vol. 7563, pp. 377-382). Saarbrücken, Germany: Springer Berlin Heidelberg. https://doi.org/10.1007/978-3642-33263-0_30

Goetz, T., Frenzel, A. C., Stoeger, H., \& Hall, N. C. (2010). Antecedents of everyday positive emotions: An experience sampling analysis. Motivation and Emotion, 34(1), 49-62. https://doi.org/10.1007/s11031-009-9152-2 
Greenberg, L. (2008). Emotion and cognition in psychotherapy: The transforming power of affect. Canadian Psychology/Psychologie Canadienne, 49(1), 49. http://dx.doi.org/10.1037/0708-5591.49.1.49

Gross, J. J. (1998). Antecedent- and response-focused emotion regulation: divergent consequences for experience, expression, and physiology. Journal of Personality and Social Psychology, 74(1), 224-237. http://dx.doi.org/10.1037//00223514.74.1.224

Gross, J. J., \& John, O. P. (2003). Individual differences in two emotion regulation processes: implications for affect, relationships, and well-being. Journal of personality and social psychology, 85(2), 348. http://dx.doi.org/10.1037/00223514.85.2.348

Gross, J. J. (2008). Emotion regulation. In Handbook of emotions (Guilford Press, Vol. 3, pp. 497-513). New-York, London: Lewis, M., Haviland-Jones, J. M., \& Barrett, L. F. (Eds.).

Hadwin, A. F., Järvelä, S., \& Miller, M. (2011). Self-regulated, co-regulated, and Socially Shared Regulation of Learning. In Handbook of Self-Regulation of Learning and Performance (Zimmerman, B., Schunk D. and Perry, N., pp. 65-82). Taylor \& Francis.

Huisman, G., van Hout, M., van Dijk, E., van der Geest, T., \& Heylen, D. (2013). LEMtool: Measuring Emotions in Visual Interfaces. In Proceedings of the SIGCHI Conference on Human Factors in Computing Systems (pp. 351-360). New York, NY, USA: ACM. https://doi.org/10.1145/2470654.2470706

Jarvela, S., \& Hadwin, A. F. (2013). New Frontiers: Regulating Learning in CSCL. Educational Psychologist, 48(1), 25-39. https://doi.org/10.1080/00461520.2012.748006

Kahneman, D. (2000). Experienced utility and objective happiness: A moment-based approach. In Choices, Values and Frames (Cambridge University Press, pp. 673692). Cambridge, UK: D. Kahneman \& A. Tversky.

Lavoué, É., Molinari, G., Prié, Y., \& Khezami, S. (2015). Reflection-in-action markers for reflection-on-action in Computer-Supported Collaborative Learning settings. Computers \& Education, 88, 129-142. https://doi.org/10.1016/j.compedu.2015.05.001

Lane, R. D., \& Schwartz, G. E. (1987). Levels of emotional awareness: A cognitivedevelopmental theory and its application to psychopathology. The American Journal of Psychiatry. https://doi.org/10.1176/ajp.144.2.133

Lane, R. D., Quinlan, D. M., Schwartz, G. E., Walker, P. A., \& Zeitlin, S. B. (1990). The Levels of Emotional Awareness Scale: A cognitive-developmental measure of 
emotion. Journal of personality assessment, 55(1-2), 124-134.

https://doi.org/10.1080/00223891.1990.9674052

Lajoie, S. P., Lee, L., Bassiri, M., Cruz-Panesso, I., Kazemitabar, M., Poitras, E., HmeloSilver, C., Wiseman, J., Chan, L., Lu, J. (2015). The role of regulation in medical student learning in small groups: Regulating oneself and others' learning and emotions. In Järvelä, S. \& Hadwin, A. (Eds.) Special issue Examining the emergence and outcomes of regulation in CSCL. Journal of Computer and Human Behavior, 52, 601-616. https://doi.org/10.1016/j.chb.2014.11.073

Leony, D., Muñoz-Merino, P. J., Pardo, A., \& Delgado Kloos, C. (2013). Provision of awareness of learners' emotions through visualizations in a computer interactionbased environment. Expert Systems with Applications, 40(13), 5093-5100. https://doi.org/10.1016/j.eswa.2013.03.030

Linnenbrink-Garcia, L., Patall, E. A., \& Pekrun, R. (2016). Adaptive Motivation and Emotion in Education Research and Principles for Instructional Design. Policy Insights from the Behavioral and Brain Sciences, 3(2), 228-236. https://doi.org/10.1177/2372732216644450

McDuff, D., Karlson, A., Kapoor, A., Roseway, A., \& Czerwinski, M. (2012). AffectAura: An Intelligent System for Emotional Memory. In Proceedings of the SIGCHI Conference on Human Factors in Computing Systems (pp. 849-858). New York, NY, USA: ACM. https://doi.org/10.1145/2207676.2208525

Meinhardt, J., \& Pekrun, R. (2003). Attentional resource allocation to emotional events: An ERP study. Cognition and Emotion, 17(3), 477-500. https://doi.org/10.1080/02699930244000039

Millard, N., \& Hole, L. (2008). Affect and Emotion in Human-Computer Interaction. In C. Peter \& R. Beale (Eds.) (pp. 186-193). Berlin, Heidelberg: Springer-Verlag. Retrieved from http://dx.doi.org/10.1007/978-3-540-85099-1_16.

Miron-Shatz, T., Stone, A., \& Kahneman, D. (2009). Memories of yesterday's emotions: Does the valence of experience affect the memory-experience gap?. Emotion, 9(6), 885 .

Molinari, G., Chanel, G., Bétrancourt, M., Pun, T., \& Bozelle, C. (2013). Emotion feedback during computer-mediated collaboration: Effects on self-reported emotions and perceived interaction. CSCL 2013: Proceedings of the 10th International Conference on Computer Supported Collaborative Learning (Vol. 1, pp. 336-344).

Paris, S. G., \& Paris, A. H. (2001). Classroom Applications of Research on Self-Regulated Learning. Educational Psychologist, 36(2), 89-101. https://doi.org/10.1207/S15326985EP3602_4

Pekrun, R. (2006). The Control-value theory of Achievement Emotions: Assumptions, 
Corollaries, and Implications for Educational Research and Practice. Educational Psychology Review, 18(4), 315-341. https://doi.org/10.1007/s10648-006-9029-9

Pekrun, R. (2014). Emotions and learning. Belley, France: International Academy of Education.

Pekrun, R., Elliot, A. J., \& Maier, M. A. (2006). Achievement goals and discrete achievement emotions: A theoretical model and prospective test. Journal of Educational Psychology, 98(3), 583. http://dx.doi.org/10.1037/t21196-000.

Pekrun, R., Elliot, A. J., \& Maier, M. A. (2009). Achievement goals and achievement emotions: Testing a model of their joint relations with academic performance. Journal of Educational Psychology, 101(1), 115-135. http://dx.doi.org/10.1037/a0013383

Pekrun, R., Goetz, T., Titz, W., \& Perry, R. P. (2002). Academic Emotions in Students' SelfRegulated Learning and Achievement: A Program of Qualitative and Quantitative Research. Educational Psychologist, 37(2), 91-105. https://doi.org/10.1207/S15326985EP3702 4

Pekrun, R. (2016). Academic emotions. Handbook of motivation at school, 2, 120-144.

Pekrun, R., Lichtenfeld, S., Marsh, H. W., Murayama, K., \& Goetz, T. (2017). Achievement emotions and academic performance: Longitudinal models of reciprocal effects. Child Development.

Pintrich, P. R. (2004). A Conceptual Framework for Assessing Motivation and SelfRegulated Learning in College Students. Educational Psychology Review, 16(4), 385-407. https://doi.org/10.1007/s10648-004-0006-x

Rheinberg, F., Vollmeyer, R., \& Rollett, W. (2000). Motivation and action in self-regulated learning. In Handbook of self-regulation (pp. 503-529).

Rieffe, C. J., Oosterveld, P., Miers, A. C., Meerum Terwogt, M., \& Ly, V. (2008). Emotion awareness and internalizing symptoms in children and adolescents; The Emotional Awareness Questionair revised. Personality and Individual Differences, 45(8), 756761. https://doi.org/10.1016/j.paid.2008.08.001

Ruiz, S., Charleer, S., Urretavizcaya, M., Klerkx, J., Fernández-Castro, I., \& Duval, E. (2016). Supporting Learning by Considering Emotions: Tracking and Visualization a Case Study. In Proceedings of the Sixth International Conference on Learning Analytics \& Knowledge (pp. 254-263). New York, NY, USA: ACM. https://doi.org/10.1145/2883851.2883888

Sander, D., Grandjean, D., \& Scherer, K. R. (2005). A systems approach to appraisal mechanisms in emotion. Neural Networks, 18(4), 317-352. https://doi.org/10.1016/j.neunet.2005.03.001

Scherer, K. R., Schorr, A., \& Johnstone, T. (2001). Appraisal Processes in Emotion: Theory, 
Methods, Research. Oxford University Press.

Sonderegger, A., Heyden, K., Chavaillaz, A., \& Sauer, J. (2016). AniSAM \& AniAvatar: Animated Visualizations of Affective States. In Proceedings of the 2016 CHI Conference on Human Factors in Computing Systems (pp. 4828-4837). New York, NY, USA: ACM. https://doi.org/10.1145/2858036.2858365

Subic-Wrana, C., Beutel, M. E., Brähler, E., Stöbel-Richter, Y., Knebel, A., Lane, R. D., \& Wiltink, J. (2014). How is emotional awareness related to emotion regulation strategies and self-reported negative affect in the general population? PloS One, 9(3), e91846. https://doi.org/10.1371/journal.pone.0091846

Sun, S., Lavoué, E., Aritajati, C., Tabard, A., Rosson, M.-B. (2019. Using and Perceiving Emoji in Design Peer Feedback. In Proceedings of the 13th international conference on Computer Supported Collaborative Learning (CSCL 2019) (pp. 296-303), Lyon, France,

Tian, F., Zhang, H., Li, L., Zheng, Q., \& Yang, Y. (2011). Visualizing e-Learner Emotion, Topic, and Group Structure in Chinese Interactive Texts. In 2011 IEEE 11th International Conference on Advanced Learning Technologies (pp. 587-589). https://doi.org/10.1109/ICALT.2011.177

Tong, E. M. W., Bishop, G. D., Enkelmann, H. C., Why, Y. P., Diong, S. M., Khader, M., \& Ang, J. (2007). Emotion and appraisal: A study using ecological momentary assessment. Cognition and Emotion, 21(7), 1361-1381. https://doi.org/10.1080/02699930701202012

Valiente, C., Swanson, J., \& Eisenberg, N. (2012). Linking students' emotions and academic achievement: When and why emotions matter. Child Development Perspectives, 6(2), 129-135. https://doi.org/10.1111/j.1750-8606.2011.00192.x

Versluis, A., Verkuil, B., Lane, R. D., Hagemann, D., Thayer, J. F., \& Brosschot, J. F. (2018). Ecological momentary assessment of emotional awareness: Preliminary evaluation of psychometric properties. Current Psychology, 1-9. https://doi.org/10.1007/s12144-018-0074-6

Volet, S., \& Vauras, M. (2013). Interpersonal Regulation of Learning and Motivation: Methodological Advances. New York, NY, USA: Routledge.

Wolters, C. A. (2003). Regulation of Motivation: Evaluating an Underemphasized Aspect of Self-Regulated Learning. Educational Psychologist, 38(4), 189-205. https://doi.org/10.1207/S15326985EP3804_1

Zimmerman, B. J. (2002). Becoming a Self-Regulated Learner: An Overview. Theory Into Practice, 41(2), 64-70. https://doi.org/10.1207/s15430421tip4102_2 
Appendix A - Emotion Recording Grid

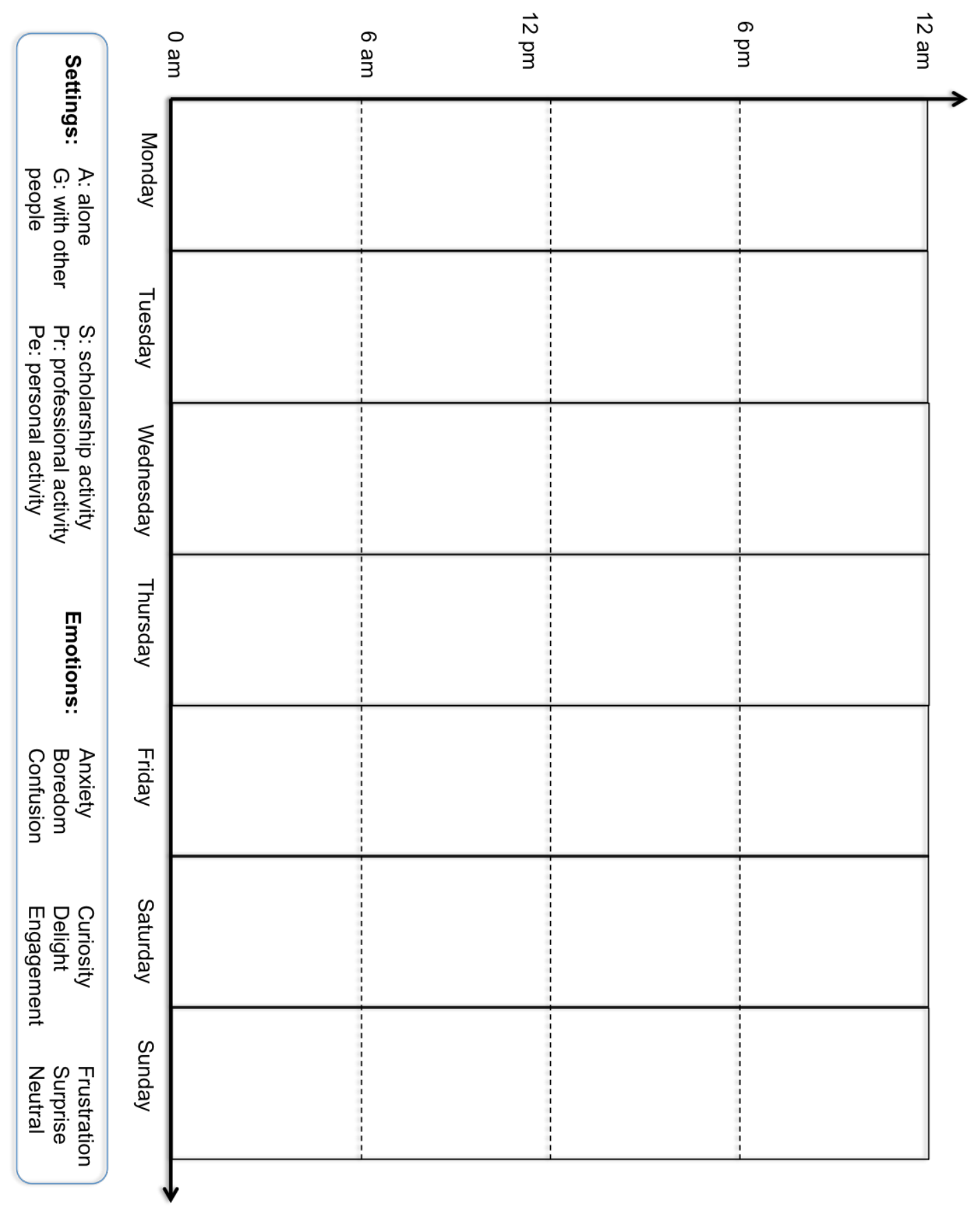




\section{Appendix B - Interviews: coding schemes}

Analysis. The analysis unit is an emotion felt by the participant.

\section{Rules:}

- We keep only academic related emotions (not professional or personal), i.e. emotions students experienced in academic situations.

- We keep non-academic emotions when accompanying academic related emotions.

- If the emotion is formulated by the interviewer, we identify it as a unit if it is linked to the content of a participant's sentence (not just rewording or inciting participant to develop ideas).

\section{Categories for coding}

\begin{tabular}{|c|c|c|c|c|}
\hline Category & Value & Definition & Code & Example \\
\hline $\begin{array}{l}\text { Emotion } \\
\text { (D'Mello et } \\
\text { al. 2014) }\end{array}$ & \multicolumn{4}{|c|}{$\begin{array}{l}\text { Anxiety, Boredom, Confusion, Curiosity, Delight, Engagement, Frustration, } \\
\text { Surprise, Neutral }\end{array}$} \\
\hline \multirow[t]{2}{*}{ Setting } & Individual & $\begin{array}{l}\text { The participant is } \\
\text { working alone (even in } \\
\text { class) }\end{array}$ & SI & $\begin{array}{l}\text { "I was a bit anxious coz I had to } \\
\text { do a lot of things" }\end{array}$ \\
\hline & Group & $\begin{array}{l}\text { The participant is } \\
\text { working in group }\end{array}$ & SG & $\begin{array}{l}\text { "I was like bored and neutral } \\
\text { because we were not doing } \\
\text { anything" }\end{array}$ \\
\hline
\end{tabular}

Academic related emotions: object focus, causalities and appraisal (Pekrun, 2006)

\begin{tabular}{|l|l|l|l|l|}
\hline Object focus & Retrospective & $\begin{array}{l}\text { Emotions pertain to the } \\
\text { outcomes of achieved activities } \\
\text { (e.g., pride or shame } \\
\text { experienced after feedback of } \\
\text { achievement) } \\
\text { Attention is on the past. }\end{array}$ & OTR & $\begin{array}{l}\text { "I felt like I was going } \\
\text { through the work at a, } \\
\text { at a decent rate, and } \\
\text { yea, so I was happy } \\
\text { about that" }\end{array}$ \\
\hline
\end{tabular}




\begin{tabular}{|c|c|c|c|c|}
\hline & Activity & $\begin{array}{l}\text { Emotions felt during ongoing } \\
\text { activities, the attentional focus } \\
\text { is on the action, not on } \\
\text { outcomes. } \\
\text { Attention is on the present. }\end{array}$ & OTA & $\begin{array}{l}\text { "I get frustrated } \\
\text { because they started } \\
\text { to talk about stuff I } \\
\text { don't remember" }\end{array}$ \\
\hline & Prospective & $\begin{array}{l}\text { Emotions pertain to the } \\
\text { outcomes of ongoing activities } \\
\text { or activities to come (e.g., hope } \\
\text { for success, anxiety of failure) } \\
\text { Attention is on the future. }\end{array}$ & OTP & $\begin{array}{l}\text { "a bit of like anxiety, } \\
\text { coz like the exam } \\
\text { coming up" }\end{array}$ \\
\hline \multirow[t]{4}{*}{ Agent } & Self & Emotion is caused by the self & AS & $\begin{array}{l}\text { "I felt anxiety, umm, } \\
\text { because I've never, } \\
\text { never did that before" }\end{array}$ \\
\hline & Others & $\begin{array}{l}\text { Emotion is caused by other } \\
\text { persons }\end{array}$ & $\mathrm{AO}$ & $\begin{array}{l}\text { "I felt anxious when I } \\
\text { realized that the } \\
\text { others were stressed } \\
\text { by the exams" }\end{array}$ \\
\hline & Group & $\begin{array}{l}\text { Emotion is caused by the } \\
\text { group, including the participant }\end{array}$ & AG & $\begin{array}{l}\text { "I was not frustrating } \\
\text { or exciting because } \\
\text { we were not doing } \\
\text { anything" }\end{array}$ \\
\hline & $\begin{array}{l}\text { External } \\
\text { Circumstances }\end{array}$ & $\begin{array}{l}\text { Emotion is caused by external } \\
\text { circumstances (independent of } \\
\text { self and others) }\end{array}$ & $\mathrm{AC}$ & $\begin{array}{l}\text { "a bit of like anxiety, } \\
\text { coz like the exam } \\
\text { coming up" }\end{array}$ \\
\hline \multirow[t]{2}{*}{$\begin{array}{l}\text { Subjective } \\
\text { value }\end{array}$} & Positive & $\begin{array}{l}\text { Positive subjective value of } \\
\text { activities and outcomes (e.g. } \\
\text { high importance of success). }\end{array}$ & PV & $\begin{array}{l}\text { "Yea I was actually } \\
\text { interested in the } \\
\text { material." } \\
\text { "This activity is very } \\
\text { important for me." }\end{array}$ \\
\hline & Negative & $\begin{array}{l}\text { Negative subjective value of } \\
\text { activities and outcomes (e.g. } \\
\text { low importance of success). }\end{array}$ & $\mathrm{NV}$ & $\begin{array}{l}\text { "This course doesn't } \\
\text { matter for me." } \\
\text { "I'm not really } \\
\text { interested in this } \\
\text { course material." }\end{array}$ \\
\hline
\end{tabular}




\begin{tabular}{|l|l|l|l|l|}
\hline $\begin{array}{l}\text { Subjective } \\
\text { control }\end{array}$ & $\begin{array}{l}\text { High } \\
\text { High subjective control over } \\
\text { achievement activities and } \\
\text { their outcomes (e.g., } \\
\text { expectations that persistence at } \\
\text { studying can be enacted, and } \\
\text { that it will lead to success) }\end{array}$ & HC & $\begin{array}{l}\text { "I can do well in } \\
\text { school if I want to" } \\
\text { "I felt engaged with } \\
\text { the material. I } \\
\text { actually understood". } \\
\text { "I feel very confident } \\
\text { about this course, I } \\
\text { have well prepared } \\
\text { the exam". }\end{array}$ \\
\cline { 2 - 3 } & Low & $\begin{array}{l}\text { Low subjective control over } \\
\text { achievement activities and } \\
\text { their outcomes (e.g., few } \\
\text { expectations about enaction of } \\
\text { activities, and that it will lead } \\
\text { to failure) }\end{array}$ & LC & $\begin{array}{l}\text { "I can't get good } \\
\text { grades no matter what } \\
\text { I do" } \\
\text { "Ifelt anxiety, umm, } \\
\text { because I've never, } \\
\text { never did that before, } \\
\text { like applying for a } \\
\text { lab, that I wasn't } \\
\text { really sure if I was } \\
\text { qualified for." }\end{array}$ \\
\hline
\end{tabular}

